\title{
Radiometric Measurements of the Microwave Emissivity of Foam
}

\author{
L. A. Rose, Member, IEEE, W. E. Asher, S. C. Reising, Member, IEEE, P. W. Gaiser, K. M. St. Germain, \\ D. J. Dowgiallo, K. A. Horgan, G. Farquharson, and E. J. Knapp
}

\begin{abstract}
Radiometric measurements of the microwave emissivity of foam were conducted during May 2000 at the Naval Research Laboratory's Chesapeake Bay Detachment using radiometers operating at 10.8 and $36.5 \mathrm{GHz}$. Horizontal and vertical polarization measurements were performed at $36.5 \mathrm{GHz}$; horizontal, vertical, $+45^{\circ},-45^{\circ}$, left-circular, and right-circular polarization measurements were obtained at $10.8 \mathrm{GHz}$. These measurements were carried out over a range of incidence angles from $30^{\circ}$ to $60^{\circ}$. Surface foam was generated by blowing compressed air through a matrix of gas-permeable tubing supported by an aluminum frame and floats. Video micrographs of the foam were used to measure bubble size distribution and foam layer thickness. A video camera was boresighted with the radiometers to determine the beam-fill fraction of the foam generator. Results show emissivities that were greater than 0.9 and approximately constant in value over the range of incidence angles for vertically polarized radiation at both 10.8 and $36.5 \mathrm{GHz}$, while emissivities of horizontally polarized radiation showed a gradual decrease in value as incidence angle increased. Emissivities at $+45^{\circ},-45^{\circ}$, left-circular, and right-circular polarizations were all very nearly equal to each other and were in turn approximately equal to the average values of the horizontal and vertical emissivities in each case.
\end{abstract}

Index Terms-Emissivity, foam, microwave radiometry, polarimetry.

\section{INTRODUCTION}

$\mathbf{F}$ OAM ON THE OCEAN surface increases the emissivity and brightness temperature measured by a passive microwave radiometer and is a key component of the wind speed signal measured by a linearly polarized radiometer. Accordingly, the accuracy of the sea foam model affects the accuracy of physical wind speed retrieval algorithms. Understanding the effect of sea foam may be of greater importance for polarimetric radiometric observations of wind direction because the azimuthal variations in brightness temperature are small, typically $1-3 \mathrm{~K}[1]-[5]$. Yueh [6] modeled the polarimetric

Manuscript received December 21, 2001; revised August 5, 2002. This work was sponsored by the Department of the Navy, Office of Naval Research under Award N0014-00-1-280 to the University of Massachusetts, Award N00014-00-0152 to the University of Washington, and Award N0001400WX21032 to the Naval Research Laboratory.

L. A. Rose, P. W. Gaiser, and K. M. St. Germain are with the Remote Sensing Division, Naval Research Laboratory, Washington DC 20375 USA.

W. E. Asher is with the Applied Physics Laboratory, University of Washington, Seattle, WA 98105 USA.

S. C. Reising, K. A. Horgan, G. Farquharson, and E. J. Knapp are with the Microwave Remote Sensing Laboratory, University of Massachusetts, Amherst MA 01003-4410 USA.

D. J. Dowgiallo is with Interferometrics, Inc., Remote Sensing Division, Naval Research Laboratory, Washington DC 20375 USA.

Digital Object Identifier 10.1109/TGRS.2002.807006 sea surface brightness temperature for the foam-free ocean and noted that "further research on the polarization signatures of foam is imperative." Kunkee [7] modeled the polarimetric surface signal by incorporating surface foam distribution and a dielectric mixing model for the foam emissivity. Differences between the dielectric mixing model and the measurements in [8] also underscore the need for further work on foam emissivity.

Although measurements of sea foam emissivity have been obtained from aircraft and ship experiments over the ocean, the surface conditions were neither controlled nor thoroughly characterized. Smith [8] determined the emissivity of sea foam based on aircraft observations of radiometric brightness temperature. Using radiometers mounted off the side of a research vessel, Vorsin et al. [9] reported measurements of sea foam brightness temperature at wavelengths of 2 and $8 \mathrm{~cm}$. Asher et al. [10] measured the average microwave emissivity of foam generated by a tipping-bucket experiment at $19 \mathrm{GHz}$ for horizontally and vertically polarized radiation in order to develop an accurate model of sea surface emissivity so that the air-sea gas transfer velocity could be related to sea surface brightness temperature. Stogryn [11] developed an empirical expression for sea foam emissivity as a function of sea surface temperature, frequency, and incidence angle based on a review of previously published measurements of foam-covered sea surfaces. Thermal radio emission from foam structures was measured in [12]; experimental and theoretical studies of foam structures have also been carried out in [13] and [14]. In addition, Guo et al. [15] used electromagnetic scattering theory to calculate the brightness temperature of foam-covered ocean surfaces. The objective of the experiment described here was to produce a set of dual-frequency measurements of the emissivity of temporally stable foam supported by a detailed characterization of the surface and foam properties.

\section{EXPERIMENT DESCRIPTION}

This experiment was conducted at the Naval Research Laboratory's Chesapeake Bay Detachment in May 2000. Fig. 1 shows the experimental setup in which a foam generator, consisting of gas-permeable tubes supported by an aluminum frame and floats, was placed on the surface of the Chesapeake Bay, approximately $7 \mathrm{~m}$ from a seawall. The foam generator was $3.0 \mathrm{~m}$ wide and $6.1 \mathrm{~m}$ long. The cradle of a telescopic arm lift was used to position two radiometers and a boresighted video camera over the water so that the foam generator could be viewed at incidence angles ranging from $30^{\circ}$ to $60^{\circ}$. The video camera was used to point the radiometers and to record 
images of foam coverage. A distance of $4.9 \mathrm{~m}$ was maintained between the radiometer antennas and the spot on the water surface at the center of the radiometer antennas' main beams. This was done in order to ensure that the generator was in the far field of the antennas and that the change in the solid angle subtended by the target foam generator was minimized as the incidence angle was varied. The University of Massachusetts radiometer, operating at $36.5 \mathrm{GHz}$, measured horizontal and vertically polarized radiation. The Naval Research Laboratory (NRL) 10.8-GHz polarimetric radiometer measured horizontal $(\mathrm{H})$, vertical $(\mathrm{V}),-45^{\circ}$ linear $(\mathrm{M}),+45^{\circ}$ linear $(\mathrm{P})$, left-circular $(\mathrm{L})$, and right-circular $(\mathrm{R})$ polarizations. Both radiometers were Dicke-switched, and both had antenna half-power (3-dB) beamwidths of approximately $7^{\circ}$. On-site calibrations of the radiometers were performed using reference loads at liquid nitrogen and ambient temperatures. Tipping curves were performed at $36.5 \mathrm{GHz}$ to utilize the cosmic background radiation as a stable cold reference source. The radiometric sensitivity was approximately $0.1 \mathrm{~K}$ for both instruments for an integration time of $0.5 \mathrm{~s}$; the data acquisition rate was $2 \mathrm{~Hz}$. The absolute error of the radiometric measurements was less than $2 \mathrm{~K}$ for the horizontal and vertical polarizations of both instruments and was less than $3 \mathrm{~K}$ for the $-45,+45$, left-circular, and right-circular polarizations of the NRL radiometer. The measurements reported in this work were carried out on May 25 and 26, 2000 under mostly clear skies with occasional patches of high cirrus clouds. The water temperature was $19^{\circ} \mathrm{C}$, and the salinity was approximately $10 \mathrm{ppt}$.

\section{VIDEO MEASUREMENTS}

A typical image recorded by the boresighted video camera is shown in Fig. 2. The fractional area foam coverage produced by the foam generator was determined from these images using the grayscale analysis procedure described in [16]. These data were used to determine how well the foam filled the surface area of the foam generator; the fractional area foam coverage was found to be $0.95 \pm 0.02$. In addition to the surface video images, such as the one shown in Fig. 2, an underwater video camera equipped with a telecentric macro zoom lens was used to photograph the bubble microstructure of the foam on the water surface. The bubble size distribution was found using images of the interior foam structure, such as that shown in Fig. 3. The total thickness of the foam layer was measured using similar images recorded at a lower magnification. The bubble size spectra and foam thickness measurements provide values to initialize numerical electromagnetic models for calculating foam emissivities, (e.g., [15]). The approximate foam layer thickness was $2.8 \mathrm{~cm}$

\section{RADIOMETRIC MEASUREMENTS}

For the purpose of this paper, antenna temperature is defined as the normalized apparent radiometric temperature at the antenna, weighted by the antenna pattern. For each polarization, the antenna temperature of the calm water surface occupied by

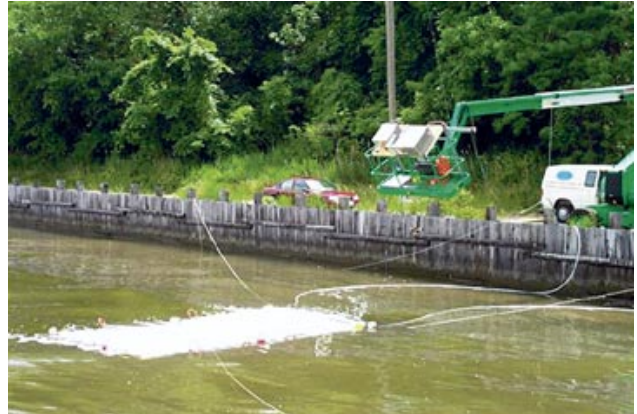

Fig. 1. Photograph of experimental setup at the Naval Research Laboratory's Chesapeake Bay Detachment showing the foam generator floating on the sea surface and the two radiometers in the cradle of a telescopic arm lift.

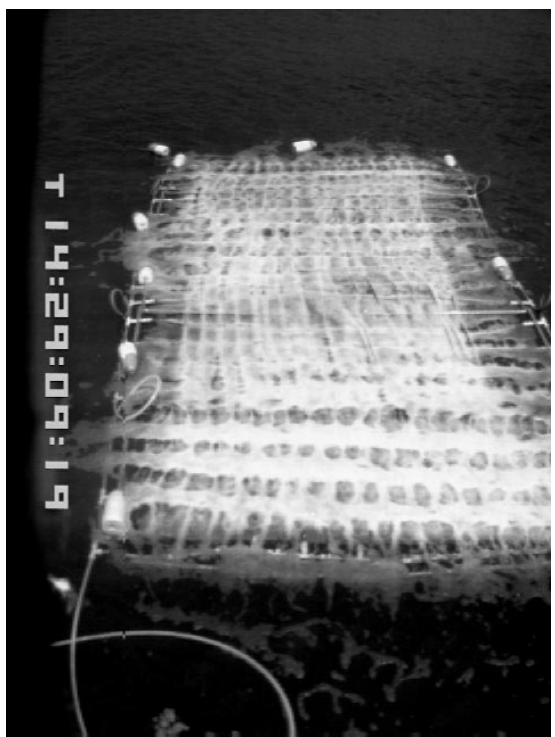

Fig. 2. Typical image of generated foam during the Chesapeake Bay experiment, as observed by the crane-mounted video camera. The incidence angle is $40^{\circ}$.

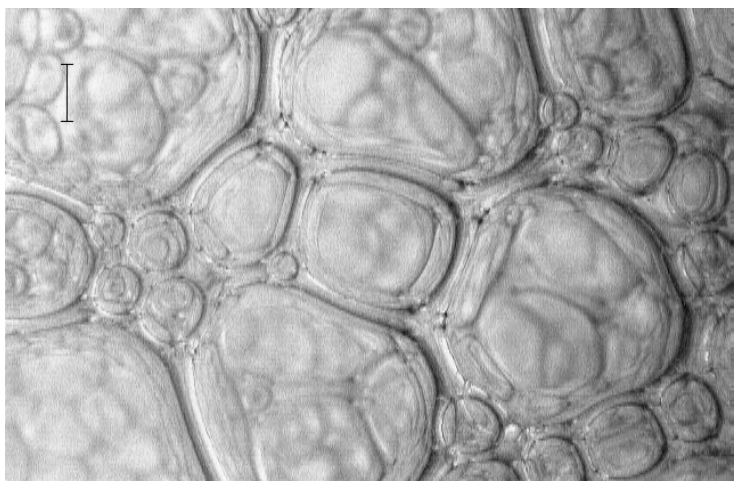

Fig. 3. Typical image of the bubble microstructure in the interior of the foam, as recorded by an underwater camera mounted near the center of the foam raft. The scale bar shown in the upper left corner represents a distance of $1000 \mu \mathrm{m}$.

the foam generator with no foam being generated can be approximated as

$$
T_{A, W}=(\eta)\left\{E_{W} T_{W}+\left(1-E_{W}\right) T_{\mathrm{SKY}}\right\}+(1-\eta) T_{\mathrm{BACK}}
$$

where

$T_{A, W}$ antenna temperature of the calm water surface; 
$\eta \quad$ beam-fill fraction of the foam generator target;

$E_{W} \quad$ emissivity of calm water surface;

$T_{W} \quad$ physical temperature of the water surface;

$T_{\mathrm{SKY}}$ brightness temperature of the downwelling sky radiation;

$T_{\mathrm{BACK}}$ effective brightness temperature of the scene outside the solid angle subtended by the target.

The quantity in braces is the radiation seen by the radiometer that is emitted and reflected from the surface area of the foam generator. The radiation emitted by the surface is the product of the surface emissivity and the surface temperature; the reflected sky radiation is represented to first order by the product of the surface reflectivity (1 - emissivity) and the downwelling sky radiation [11]. For the case when foam is generated on the water surface

$$
\begin{aligned}
T_{A, F}= & (\eta)\left\{(f) E_{F} T_{W}+(1-f) E_{W} T_{W}+(f)\left(1-E_{F}\right) T_{\mathrm{SKY}}\right. \\
& \left.+(1-f)\left(1-E_{w}\right) T_{\mathrm{SKY}}\right\}+(1-\eta) T_{\mathrm{BACK}}
\end{aligned}
$$

where

$T_{A, F}$ antenna temperature of foam-covered water surface;

$f$ fraction of generator surface covered by foam;

$E_{F} \quad$ emissivity of foam-covered water surface.

In this analysis, it is assumed that the physical temperature of the foam and the water surface are the same, and it is also assumed that the total brightness temperature of the target foam generator may be separated into a foam-covered portion and a foam-free portion. The value of the downwelling brightness temperature $\left(T_{\mathrm{SKY}}\right)$ was approximated by the antenna temperature measuremen $\left(T_{A, \mathrm{SKY}}\right)$ obtained by pointing the radiometer upward at the specular angle. Subtracting (1) from (2) yields the following expression for the difference between the emissivities of a foam-covered surface and a smooth foam-free water surface:

$$
E_{F}-E_{W}=\frac{T_{A, F}-T_{A, w}}{(\eta)(f)\left(T_{W}-T_{A, \mathrm{SKY}}\right)}
$$

where $T_{\mathrm{SKY}}$ was approximated by $T_{A, \mathrm{SKY}}$. A separate measurement of the calm water surface, looking away from the foam generator but at the same incidence angle, for which it is assumed that the water surface completely fills the antenna field of view so that $\eta=1$, gives

$$
T_{A, W}=\left(E_{W}\right) T_{W}+\left(1-E_{W}\right) T_{\mathrm{SKY}}
$$

and

$$
E_{W}=\frac{T_{A, W}-T_{A, \mathrm{SKY}}}{T_{W}-T_{A, \mathrm{SKY}}}
$$

where $T_{\mathrm{SKY}}$ in (4) was again replaced by $T_{A, \mathrm{SKY}}$. In practice, the measurements of antenna temperature of water looking to the side of the generator usually agreed with the calm-water measurements of the foam generator itself to within 1 or $2 \mathrm{~K}$, showing that the gas-permeable tubes, frame, and floats of the generator contributed very little to the background radiation. For each polarization, the emissivities of a calm water surface and a foam-covered water surface were calculated using (5) and (3), respectively.

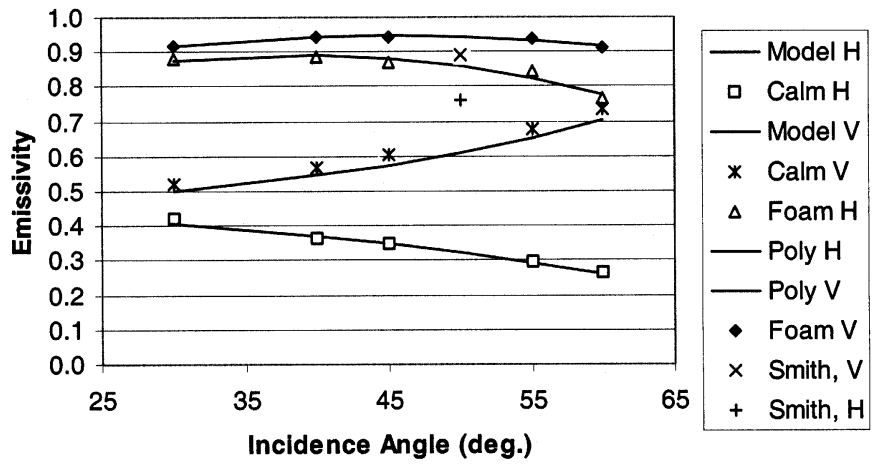

Fig. 4. Foam and calm-water emissivities at $36.5 \mathrm{GHz}$, vertical and horizontal polarization. The curves labeled "Poly V" and "Poly H" are the polynomial fits to the V and $\mathrm{H}$ foam emissivity data, respectively. "Calm V" and "Calm $\mathrm{H}$ " are the calm-water experimental results; "Model V" and "Model H" are modeled emissivity curves based on the Fresnel reflection coefficients of calm water [17]. The data points labeled "Smith, V" and "Smith, H" are from aircraft measurements over the ocean at an incidence angle of $50^{\circ}$ [8].

The beam-fill fraction of the foam generator target is

$$
\eta=\frac{\iint_{\mathrm{TARGET}} F(\theta, \vartheta) d \Omega}{\iint_{4 \pi} F(\theta, \vartheta) d \Omega}
$$

where $F(\theta, \vartheta)$ is the normalized antenna pattern. Digitized antenna patterns were used to perform the integrations; the limits of integration were determined from the video images of the foam generator and the geometry of the experimental setup. Beam-fill fractions ranged from 0.97 at $30^{\circ}$ incidence angle to 0.93 at $60^{\circ}$ incidence angle.

\section{EXPERIMENTAL RESULTS}

Fig. 4 shows $36.5-\mathrm{GHz}$ emissivity results for vertical (V) and horizontal $(\mathrm{H})$ polarizations where (5) and (3) have been used to compute the emissivities of calm water and foam-covered water surfaces. Model calm-water emissivities using the permittivity of seawater at microwave frequencies and based on the Fresnel reflection coefficients of calm water [17] were compared to experimental results with good agreement. The $\mathrm{V}$ polarization emissivity of the foam-covered surface was roughly constant at $\sim 0.93$ over the range of incidence angles, but the $\mathrm{H}$ polarization emissivity decreased gradually from $\sim 0.88$ at $30^{\circ}$ incidence to $\sim 0.77$ at $60^{\circ}$ incidence angle. This decrease in emissivity with incidence angle somewhat resembles the calm-water $\mathrm{H}$ polarization results except that the foam emissivities are approximately 0.5 greater than the calm-water values. A power-series polynomial of the form

$$
E_{F}=a_{0}+a_{1}(\theta)+a_{2}(\theta)^{2}
$$

was used to fit the foam emissivity versus incidence angle data. Here $a_{0}, a_{1}$, and $a_{2}$ are the coefficients of the series, and $\theta$ is the incidence angle in degrees. Table I provides the $\mathrm{H}$ and $\mathrm{V}$ model coefficients for the $36.5-\mathrm{GHz}$ observations, and the polynomial fits are shown in Fig. 4. Foam emissivity measurements at $50^{\circ}$ incidence angle are not shown in Fig. 4 due to a pointing error that occurred during that particular measurement.

Fig. 5 shows the surface foam $\mathrm{V}$ and $\mathrm{H}$ emissivities and polynomial fits at $10.8 \mathrm{GHz}$, along with modeled and measured 
TABLE I

COEFFICIENTS OF THE POWER-SERIES MOdEL FunCtion AT $36.5 \mathrm{GHz}$

\begin{tabular}{c|c|c|r}
\hline Polarization & \multicolumn{1}{|c|}{$a_{0}$} & $a_{1}$ & $a_{2}$ \\
\hline $\mathrm{H}$ & 0.5601 & 0.01747 & $-2.306 \mathrm{e}-4$ \\
\hline $\mathrm{V}$ & 0.6696 & 0.01223 & $-1.352 \mathrm{e}-4$ \\
\hline
\end{tabular}

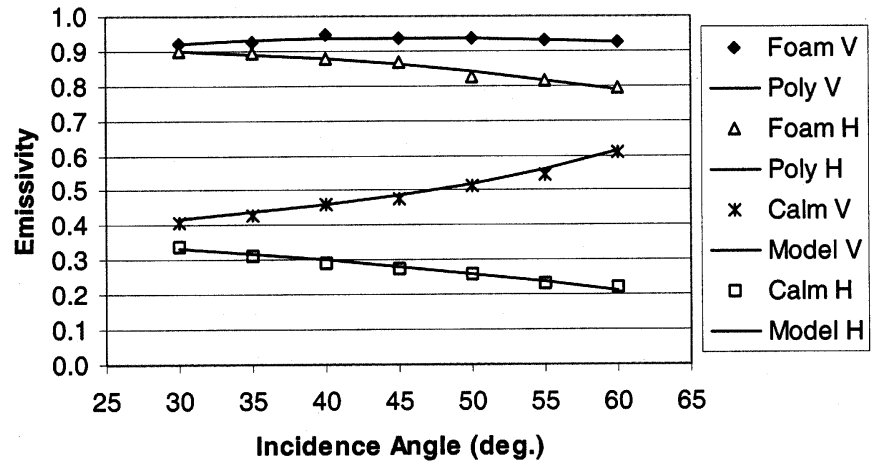

Fig. 5. Foam and calm-water emissivity at $10.8 \mathrm{GHz}$, vertical and horizontal polarization. "Poly V" and "Poly H" are the polynomial fits to the $\mathrm{V}$ and $\mathrm{H}$ foam emissivity data, respectively. "Calm V" and "Calm H" are the calm-water experimental results; "Model V" and "Model H" are modeled emissivity curves based on the Fresnel reflection coefficients of calm water [17].

TABLE II

COEFFICIENTS OF THE POWER-SERIES MOdel FunCtION AT $10.8 \mathrm{GHz}$

\begin{tabular}{c|c|c|c}
\hline Polarization & $a_{0}$ & $a_{1}$ & $a_{2}$ \\
\hline $\mathrm{H}$ & 0.8962 & 0.002159 & $-6.572 \mathrm{e}-5$ \\
\hline $\mathrm{V}$ & 0.7864 & 0.006696 & $-7.329 \mathrm{e}-5$ \\
\hline $\mathrm{M}$ & 0.7504 & 0.007478 & $-9.665 \mathrm{e}-5$ \\
\hline $\mathrm{P}$ & 0.6878 & 0.01064 & $-1.353 \mathrm{e}-4$ \\
\hline $\mathrm{L}$ & 0.7485 & 0.007729 & $-1.019 \mathrm{e}-4$ \\
\hline $\mathrm{R}$ & 0.7220 & 0.009183 & $-1.209 \mathrm{e}-4$ \\
\hline
\end{tabular}

emissivities of calm water. The results are very similar to those at $36.5 \mathrm{GHz}$ : the $\mathrm{V}$ emissivity of foam is approximately constant at 0.93; the $\mathrm{H}$ emissivities exhibit a gradual decrease as incidence angle increases, similar to that of the calm-water results, but displaced upward by approximately 0.55 . The polynomial coefficients at $10.8 \mathrm{GHz}$ for $\mathrm{H}, \mathrm{V}, \mathrm{M}, \mathrm{P}, \mathrm{L}$, and $\mathrm{R}$ polarizations are given in Table II. Figs. 6 and 7 show $10.8-\mathrm{GHz}$ foam emissivity plots for $-45^{\circ}$ linear (M) and left-circular (L) polarization, respectively, with model and measured emissivities of calm water, and the polynomial fit to the foam emissivity data also shown. Plots of $+45^{\circ}$ linear and right-circular polarization emissivities were so close in value to $-45^{\circ}$ and left-circular that they are not shown. The $-45^{\circ}$ linear and left-circular polarization plots agree fairly well with each other; they are in turn roughly in agreement with the average values of the foam $\mathrm{H}$ and $\mathrm{V}$ emissivities at $10.8 \mathrm{GHz}$ shown in Fig. 5. Uncertainties in the measurement of antenna temperature, foam fraction, and beam-fill fraction were the primary sources of error in the determination of emissivity. The absolute calibration of the radiometers was in the range \pm 2 to $\pm 3 \mathrm{~K}$; the uncertainty in foam fraction was \pm 0.02 ; and the uncertainty in beam-fill fraction was \pm 0.02 . Propagation of these uncertainties through the calculations of $E_{W}$ and $E_{F}$ produced overall errors in the computed emissivities of \pm 0.02 for the $\mathrm{H}$ and $\mathrm{V}$ polarizations and of \pm 0.03 for the $\mathrm{P}, \mathrm{M}, \mathrm{L}$, and $\mathrm{R}$ polarizations [18, $\mathrm{p}$. $41-43]$.

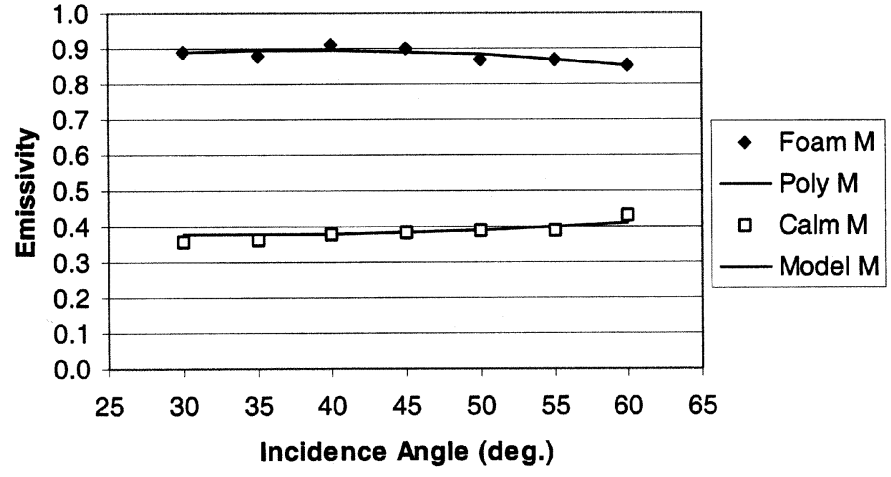

Fig. 6. Foam and calm-water emissivity at $10.8 \mathrm{GHz}$ for $-45^{\circ}$ linear (M) polarization. "Poly M" is the polynomial fit to the M foam emissivity data. "Calm M" represents the experimental results for calm water. The "Model M" results are based on the Fresnel reflection coefficients of calm sea water [17].

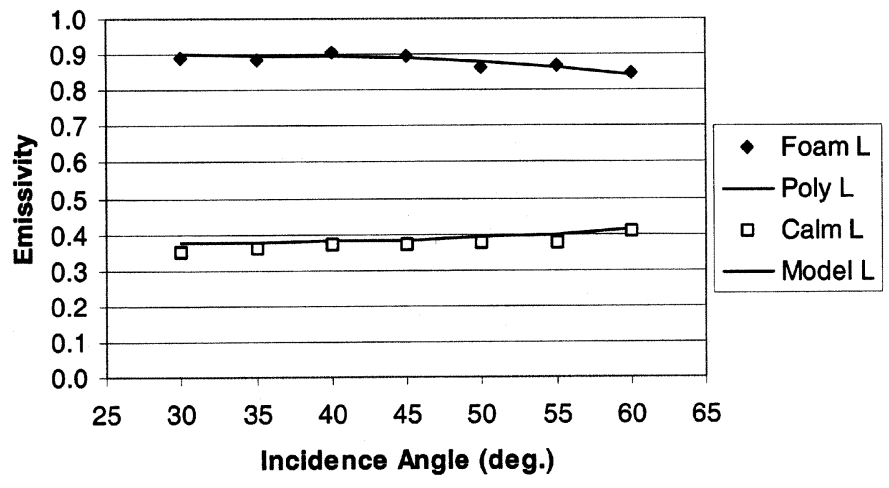

Fig. 7. Foam and calm-water emissivity at $10.8 \mathrm{GHz}$ for left-circular (L) polarization. "Poly L" is the polynomial fit to the L foam emissivity data. "Calm L" represents the experimental results for calm water. The "Model L" results are based on the Fresnel reflection coefficients of calm sea water [17].

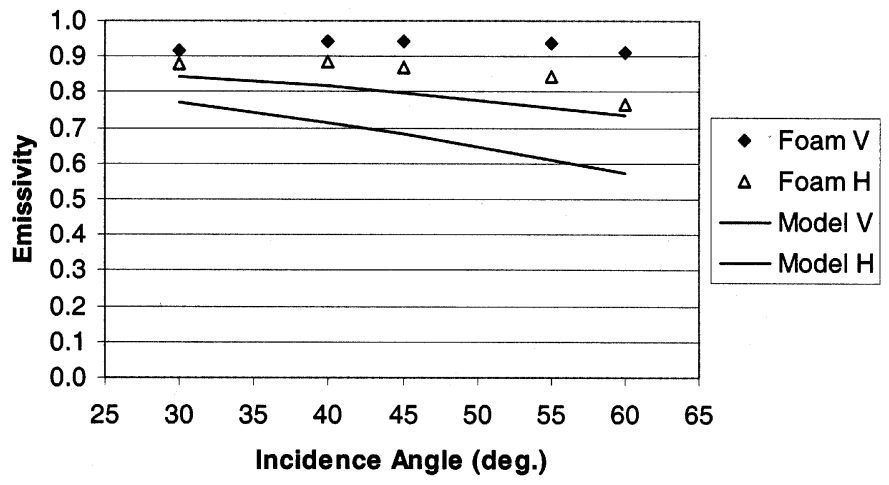

Fig. 8. Curves labeled "Model V" and "Model $\mathrm{H}$ " are values of foam emissivity at $36.5 \mathrm{GHz}$ computed from Stogryn [11]. "Foam V" and "Foam H" are the $36.5-\mathrm{GHz} \mathrm{V}$ and $\mathrm{H}$ foam emissivities, identical to data shown in Fig. 4.

We now compare our measurements with the empirical expressions given in [11], which are frequently cited in the literature. The values of these analytic expressions are plotted as a function of incidence angle in Fig. 8 at a frequency of $36.5 \mathrm{GHz}$, along with the $\mathrm{H}$ and $\mathrm{V}$ results from Fig. 4. Fig. 9 is a similar comparison of the 10.8-GHz results from Fig. 5 with the values of Stogryn's analytic expressions. His equations were developed based on data in the 13.4-37-GHz range, but he considered extrapolations to the range 3-50 GHz to be valid. At both frequencies, his equations predict emissivities that are smaller than 


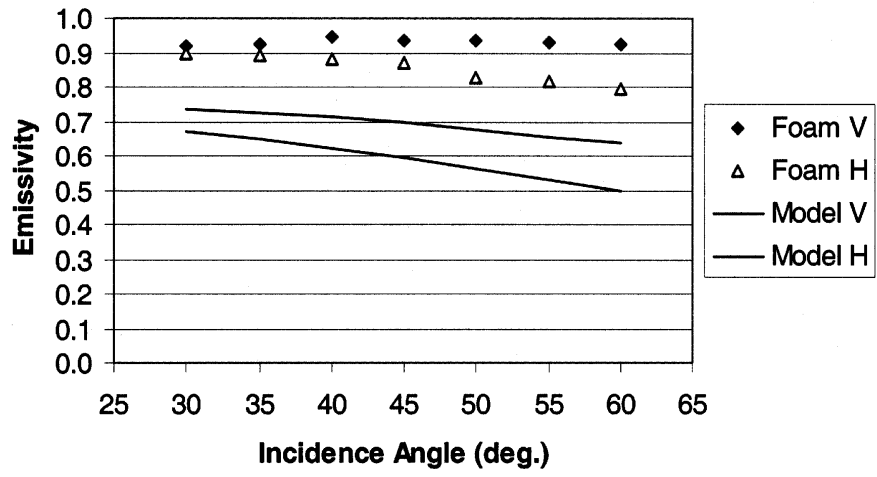

Fig. 9. Curves labeled "Model V" and "Model H" are values of foam emissivity at $10.8 \mathrm{GHz}$ computed from Stogryn [11]. "Foam V" and "Foam H" are the $10.8-\mathrm{GHz} \mathrm{H}$ and $\mathrm{V}$ foam emissivities, identical to data shown in Fig. 5.

the observed values. In addition, the angular dependence of his model shows a slight decrease in vertically polarized emissivity with incidence angle that is not observed in the experimental results at either frequency. The slopes of his $\mathrm{H}$ polarization curves, however, are somewhat similar to the slopes of the experimental curves. Stogryn's relations were developed using cases of artificially generated and naturally occurring foam. At least three possible explanations exist for why his analytic expressions give smaller values of emissivity: overestimate of foam fraction [19], radiometer calibration errors, or significantly thinner layers of foam than the ones used in this experiment.

From his airborne experiment, Smith [8] found the maximum values of $37-\mathrm{GHz}$ sea foam emissivity at $\mathrm{H}$ and $\mathrm{V}$ polarization to be 0.76 and 0.89 , respectively. His measurements, performed at an incidence angle of $50^{\circ}$, and shown in Fig. 4, are lower than the values measured in this experiment but are also larger than emissivities predicted by the Stogryn model. For a wavelength of $2 \mathrm{~cm}$, at vertical polarization, Vorsin et al. [9] reported an experimental emissivity of 0.985 at an incidence angle of $55^{\circ}$ when looking at foam from breaking waves in the Black Sea.

Based on a simple physical model for the geometric structure of foam, Droppleman [20] predicted emissivities of sea foam at normal incidence for the frequencies $1.4,10,19$, and $34 \mathrm{GHz}$. He showed that for ratios of foam thickness to wavelength greater than approximately 0.7 , the sea foam emissivity may be greater than 0.9 if the ratio of air volume to total foam volume $(\mathrm{R})$ is in the range $0.95-0.99$. In this experiment, the ratios of foam thickness to electromagnetic wavelength at 10.8 and $36.5 \mathrm{GHz}$ were approximately 1.0 and 3.4, respectively. Analysis of video images such as those shown in Fig. 3 found that $\mathrm{R}=0.85$ in the center of the foam layer. However, it is known that $\mathrm{R}$ increases as foam ages and water drains from the interstitial areas [21], and the foam at the surface is older than in the core where $\mathrm{R}$ was measured. Because of this drainage effect, the value of $\mathrm{R}$ on the surface of the foam layer is likely to be higher than in the core region, possibly approaching a value of 0.95 .

By observing the decrease in brightness temperature of a layer of foam on a smooth water surface as the layer disintegrates, Militskii et al. [12] have shown that approximately $85 \%$ to $90 \%$ of the initial increase in brightness temperature that occurs when the surface is covered in foam is still seen when the foam has decayed until a stable monolayer emulsion gas bubble structure is left on the surface. They concluded that the monolayer on the water surface acted as a transition layer and that diffraction effects contributed substantially to the dissipation of microwave energy. Additional foam structure above the monolayer increases the diffraction loss, resulting in a surface of high emissivity. The relatively high values of emissivity measured in this experiment are consistent both with Droppleman's work and with the results reported by Militskii et al., since the present measurements of surface foam were performed with a thickness of approximately one wavelength or greater at both frequencies of observation.

The salinity of the water for this experiment was approximately $10 \mathrm{ppt}$, whereas the salinity of sea water is in the range 30-36 ppt. For the frequencies used in this experiment, the change in model calm-water emissivity as the salinity varies from 10-35 ppt is approximately 0.001, but the change in emissivity of ocean foam as a function of salinity has not been explored. A future experiment using a foam generator in water with a salinity of $35 \mathrm{ppt}$ is planned in order to address this topic.

\section{SUMMARY}

Radiometric measurements of foam at 10.8 and $36.5 \mathrm{GHz}$ were performed using a foam generator floating on the seawater surface and two microwave radiometers mounted on a telescopic arm lift in order to view the foam generator at incidence angles from $30^{\circ}$ to $60^{\circ}$. The foam layer thickness was approximately $2.8 \mathrm{~cm}$. The $36.5-\mathrm{GHz}$ radiometer measured horizontally and vertically polarized radiation; the $10.8-\mathrm{GHz}$ radiometer measured horizontal, vertical, $-45^{\circ},+45^{\circ}$, left-circular, and right-circular polarizations. The $10.8-$ and $36.5-\mathrm{GHz}$ vertically polarized foam emissivities were greater than 0.9 over the range of incidence angles observed. At horizontal polarization, both the 10.8 - and $36.5-\mathrm{GHz}$ emissivities were lower than the vertically polarized emissivities and gradually decreased as the incidence angle increased. At $10.8 \mathrm{GHz}$, the $-45^{\circ},+45^{\circ}$, left-circular, and right-circularly polarized emissivities were all approximately equal to each other and agreed well with the averages of vertical and horizontal polarization emissivities.

\section{ACKNOWLEDGMENT}

The authors thank R. Fogelberg (University of Washington's Applied Physics Laboratory, Seattle) for assistance in performing the measurements, as well as C. Swift (University of Massachusetts, Amherst, MA) and two anonymous reviewers for their helpful remarks.

\section{REFERENCES}

[1] P. S. Chang, P. W. Gaiser, L. Li, and K. M. St. Germain, "Multi-frequency polarimetric microwave ocean wind direction retrievals," in Proc. IGARSS, Singapore, 1997, pp. 1009-1011.

[2] S. Yueh, W. J. Wilson, F. K. Li, W. Ricketts, and S. V. Ngheim, "Polarimetric brightness temperatures of sea surfaces measured with K-band and Ka-band radiometers," IEEE Trans. Geosci. Remote Sensing, vol. 35, pp. 1177-1187, Sept. 1997.

[3] S. Yueh, W. J. Wilson, S. J. Dinardo, and F. K. Li, "Polarimetric microwave brightness signatures of ocean wind directions," IEEE Trans. Geosci. Remote Sensing, vol. 37, pp. 949-959, Mar. 1999. 
[4] J. R. Piepmeier and A. J. Gasiewski, "High-resolution passive polarimetric microwave mapping of ocean surface wind vector fields," IEEE Trans. Geosci. Remote Sensing, vol. 39, pp. 606-622, Mar. 2001.

[5] —_, "Digital correlation microwave polarimetry," IEEE Trans. Geosci. Remote Sensing, vol. 39, pp. 2392-2410, Nov. 2001

[6] S. Yueh, "Modeling of wind direction signals in polarimetric sea surface brightness temperatures," IEEE Trans. Geosci. Remote Sensing, vol. 35, pp. 1400-1418, Nov. 1997.

[7] D. B. Kunkee, "Ocean surface foam modeling for passive remote sensing of ocean surface wind vectors," in Proc. IGARSS, vol. 5, Seattle, WA, July 1998 , pp. 2336-2338

[8] P. M. Smith, "The emissivity of sea foam at 19 and $37 \mathrm{GHz}$," IEEE Trans. Geosci. Remote Sensing, vol. 26, pp. 541-547, Sept. 1988.

[9] N. N. Vorsin, A. A. Glotov, V. G. Mirovskii, V. Yu. Raizer, I. A. Troitskii, E. A. Sharkov, and V. S. Etkin, "Direct radiometric measurements of sea foam," Sov. J. Remote Sens., vol. 2, no. 3, pp. 520-525, 1984.

[10] W. Asher, Q. Wang, E. C. Monahan, and P. M. Smith, "Estimation of air-sea gas transfer velocities from apparent microwave brightness temperature," Marine Tech. Soc. J., vol. 32, no. 2, pp. 32-40, 1998.

[11] A. Stogryn, "The emissivity of sea foam at microwave frequencies," J.Geophys. Res., vol. 77, no. 9, pp. 1658-1666, Mar. 1972.

[12] Yu. A. Militskii, V. Yu. Raizer, E. A. Sharkov, and V. S. Etkin, "Thermal radio emission from foam structures," Sov. Phys. Tech. Phys., vol. 23, no. 5, pp. 601-602, May 1978.

[13] G. S. Bordonskiy, I. B. Vasil'kova, V. M. Veselov, N. N. Vorsin, Yu. A. Militskii, V. G. Mirovskiy, V. V. Nikitin, V. Yu. Raizer, Yu. B. Khapin, Ye. A. Sharkov, and V. S. Etkin, "Spectral characteristics of the emissivity of foam formations," Izvestiya, Atmos. Ocean Phys., vol. 14, no. 6, pp. 464-469, 1978

[14] V. Yu. Raizer and E. A. Sharkov, "Electrodynamic description of densely packed dispersed systems," Izvestiva, Radiophys. Quantum Electron., vol. 24, no. 7, pp. 553-560, July 1981.

[15] J. Guo, L. Tsang, W. Asher, K.-H. Ding, and C.-T. Chen, "Applications of dense media radiative transfer theory for passive microwave remote sensing of foam covered ocean," IEEE Trans. Geosci. Remote Sensing, vol. 39, pp. 1019-1027, May 2001.

[16] W. E. Asher and R. Wanninkhof, "The effect of bubble-mediated gas transfer on purposeful dual gaseous tracer experiments," J. Geophys. Res., vol. 103, no. 10, pp. 555-560, May 1998.

[17] L. A. Klein and C. T. Swift, "An improved model for the dielectric constant of sea water at microwave frequencies," IEEE Trans. Antennas Propagat., vol. 25, no. 1, pp. 104-111, 1977.

[18] P. R. Bevington and D. K. Robinson, Data Reduction and Error Analysis for the Physical Sciences. New York: McGraw-Hill, 1992.

[19] W. Nordberg, J. Conaway, D. B.Duncan B. Ross, and T. Wilheit, "Microwave emission from a foam-covered, wind-driven sea," J. Atmos. Sci., vol. 28, pp. 429-435, Apr. 1971.

[20] J. D. Droppleman, "Apparent microwave emissivity of sea foam," $J$. Geophys. Res., vol. 75, no. 3, pp. 696-698, Jan. 1970.

[21] S. Berkman and G. Egloff, Emulsions and Foams. New York: Reinhold, 1941.

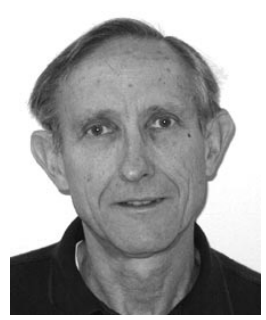

L. A. Rose (S'60-M'61) received the B.S.E.E. degree from the University of Arkansas, Fayetteville, the M.S. degree in physics from Vanderbilt University, Nashville, TN, and the Ph.D. degree in astrophysics from the University of Minnesota, Minneapolis.

$\mathrm{He}$ is currently a Research Physicist in the Microwave Remote Sensing Section, Remote Sensing Division, Naval Research Laboratory (NRL), Washington, DC. He has prepared a set of SSM/I simulator radiometers and has conducted a series of NRL RP-3A aircraft underflight measurements in support of the Navy's initial calibration of the DMSP SSM/I passive microwave sensors. He has performed many field and aircraft experiments to study the emission of microwave radiation from land and water surfaces.

Dr. Rose is a member of the American Astronomical Society and the American Geophysical Union.

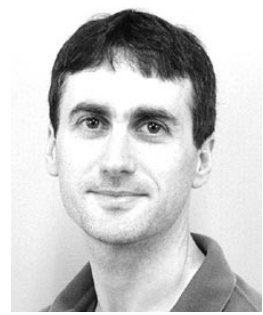

W. E. Asher received the B.A. degree in chemistry from Reed College, Portland, OR, in 1980, and the Ph.D. degree in environmental science and engineering from Oregon Graduate Institute for Science and Technology, Beaverton, OR, in 1987.

His is currently a Senior Oceanographer at the Applied Physics Laboratory, University of Washington, Seattle, and a Staff Scientist at the Department of Environmental Science and Engineering, Oregon Health and Sciences University, Beaverton. His research interests include characterization of breaking waves, air-sea transfer processes, and modeling the formation of secondary organic aerosols. He is an Associate Editor for the Journal of Geophysical Research Oceans (American Geophysical Union) and an editor for Atmospheric Chemistry and Physics (European Geophysical Society)

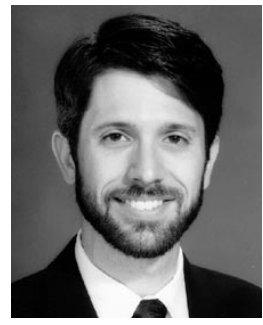

S. C. Reising (S'93-M'98) received the B.S. and M.S. degrees in electrical engineering from Washington University, St. Louis, MO, in 1989 and 1991, respectively. He received the Ph.D. degree from Stanford University, Stanford, CA, in 1998, where his dissertation research focused on low-frequency remote sensing of lightning and its energetic coupling to the ionosphere, producing chemical changes and optical emissions.

Since 1998, he has been an Assistant Professor of electrical and computer engineering at the University of Massachusetts, Amherst. His technical interests include microwave/millimeterwave remote sensing, particularly of the ocean and atmosphere, as well as radiometer design and miniaturization using MMIC architectures. During 1999 and 2000, he was a Navy-ASEE Summer Faculty Fellow at the Naval Research Laboratory, Washington, DC, and he currently serves as a member of the WindSat Science Team. He is the current Editor and past Associate Editor of the IEEE Geoscience and Remote Sensing Society (GRS-S) Newsletter.

Dr. Reising received the URSI/USNC Best Student Paper Prize at the National Radio Science Meeting in Boulder, CO, in 1998. In 2000, he won an Office of Naval Research Young Investigator Award (YIP). He was awarded a Lilly Teaching Fellowship in 2001-2002. He is an ex-officio member of the GRS-S AdCom (without vote). He serves as Chair of the Springfield, MA, Joint Chapter of the IEEE AP, GRS, ED, MTT, and LEO Societies. He is a Member of URSI Commissions F, G, and $\mathrm{H}$, and is the Commission F Co-Chair of the International URSI Working Group on Solar Power Satellites. He is a member of the American Meteorological Society, the American Geophysical Union, Tau Beta Pi, and Eta Kappa Nu.

P. W. Gaiser received the B.S. degree in electrical engineering from Virginia Tech, Blacksburg, in 1987, and the Ph.D. degree from the University of Massachusetts, Amherst, in 1993, where he studied microwave remote sensing, with emphasis on synthetic aperture interferometric radiometry.

He has been with the Naval Research Laboratory (NRL), Washington, DC, since 1993, and currently heads the Microwave Remote Sensing Section, Remote Sensing Division at NRL. While at NRL, he has been involved in polarimetric radiometry research. His research interests also include instrument design, data collection, and model development specifically for the purpose of ocean wind vector measurements from space $\mathrm{He}$ is the Principal Investigator for the WindSat spaceborne polarimetric microwave radiometer demonstration project.

K. M. St. Germain, photograph and biography not available at the time of publication. 


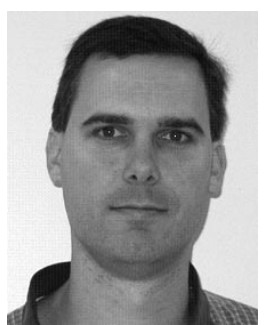

D. J. Dowgiallo received the B.S. degree in electrical engineering from George Mason University, Fairfax, $\mathrm{VA}$, in 2001 .

He has been with the Naval Research Laboratory, Washington, DC, since 1995, where he supports the Passive Remote Sensing Group. His activities focus on radiometer development for aircraft and space platforms that are used for ocean and atmosphere modeling. His work has included instruments that have been deployed successfully to remote regions including land, air, and sea. The demanding applications have led to a number of custom circuits that he has designed and implemented in several field campaigns.

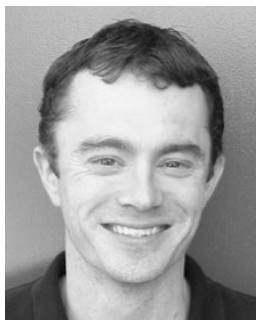

K. A. Horgan was born in Tralee, Ireland, on $\mathrm{Au}-$ gust 25,1975 . He received the B.S.E.E. (with honors) from the University of Massachusetts, Amherst, in 1999, where he is currentlyt pursuing the M.S.E.E. degree.

$\mathrm{He}$ is currently a Research Assistant in the Microwave Remote Sensing Laboratory, University of Massachusetts. His research activity focuses on the development of a Ka-band polarimetric microwave radiometer and polarimetric calibration techniques.

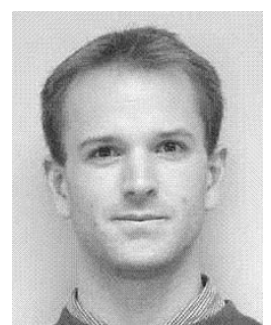

G. Farquharson (M'98-SM'99) received the B.S. (Eng.) and M.S. (Eng.) degrees from the University of Cape Town, Cape Town, South Africa, in 1996 and 1999, respectively. He is currently pursuing the Ph.D. degree in electrical engineering at the Microwave Remote Sensing Laboratory (MIRSL), University of Massachusetts, Amherst.

During his Master's degree he worked on the development of a ground-penetrating radar system at the Radar Remote Sensing Laboratory, University of Cape Town. At MIRSL, he is involved in remote sensing of the ocean surface with both ground-based and airborne microwave radars.

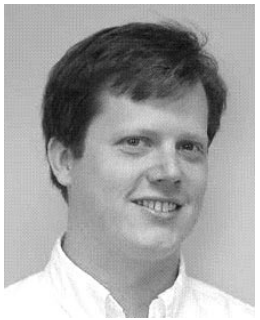

E. J. Knapp received the B.S. degree in electrical engineering from Washington University, St. Louis, MO, in 1990. He received the M.S.E.C.E. from the University of Massachusetts, Amherst, in 1993.

He is currently a Senior Research Engineer in the Electrical and Computer Engineering Department at the University of Massachusetts. His research interests include active and passive microwave remote sensing instrumentation and embedded computer systems. 